\title{
Awards Presented at the 49th Annual Meeting of the BEHAVIOR GENETICS ASSOCIATION
}

\author{
June 29th, Stockholm, Sweden
}

(c) Springer Science+Business Media, LLC, part of Springer Nature 2019

The Association's annual awards were presented at the Banquet. President-Elect Meike Bartels served as the master of ceremonies.

The 42nd Annual Thompson Award for the best oral presentation by an associate member was presented by Antti Latvala to Kirstin Purves for the presentation entitled "The heritability of fear conditioning as a model for anxiety disorder and treatment response".

The 7th Annual Rowe Award for the best poster presentation by an associate member was presented by Eric Turkheimer to Chaoyu Kate Liu for the poster entitled "Disentangle the bidirectional relationship between ADHD and $B M I$ with different genetically informative approaches".

The 16th Annual Fuller and Scott Award for outstanding early career contributions to the field was presented by PastPresident Deborah G. Finkel to Michel Nivard.

The 19th Annual Fulker Award for the outstanding paper in Behavior Genetics during the past year was presented by
John Hewitt, to Camelia Minica for the paper "Extending causality tests with genetic instruments: An integration of Mendelian randomization with the classical twin design".

The 42nd annual Dobzhansky Award for outstanding lifetime contributions to the field of behavior genetics was presented to Jack McArdle and Carol Prescott by Past-President Deborah G. Finkel.

Respectfully Submitted,

Timothy Bates

Secretary, Behavior Genetics Association

Deborah G. Finkel

Past President, Chair of the BGA Awards Committee

Publisher's Note Springer Nature remains neutral with regard to jurisdictional claims in published maps and institutional affiliations. 